\title{
GC/MS Method for Detecting 8 Kinds of Pesticide Residues in Organic Vegetables
}

\author{
Wang Dan \\ Food Science and Engineering College \\ Beijing University of Agriculture \\ Beijing, China \\ e-mail: 1345100598@qq.com
}

\author{
Zhao Jianzhuang*, Liang Dan \\ Biological sciences and College, Beijing University of \\ Agriculture \\ Beijing, China \\ e-mail:\{zhaojianzhuang, liangdan\}@bua.edu.cn \\ *Corresponding author
}

\begin{abstract}
Objective to established a gas chromatography mass spectrometry method for the determination of the 8 phosphorus and carbamates pesticide residues in organic vegetables. The vegetable sample was homogenate, after the extraction of acetonitrile. The detection of the GC/MS was carried out by solid phase extraction column. The mass spectra of 8 kinds of organic phosphorus and organic amino acid esters of formic acid esters are effective, the detection limit was $0.003 \sim 0.008 \mathrm{mg} / \mathrm{kg}$. The average recoveries of the 8 pesticides were from $74.7 \%$ to $93.2 \%$ in the range of $0.025 \sim 1 \mathrm{mg} / \mathrm{kg}$. The relative standard deviation was from $8.08 \%$ to $9.17 \%$. This method is simple for sample treatment, with a good purifying effect and ease popularization, and it can provide a method for the determination of organic phosphorus and pesticide residues in vegetables.
\end{abstract}

Keywords-organic vegetable; solid-phase; GC/MS; pesticide residues

\section{INTRODUCTION}

China has begun to use pesticides 2000 years ago, with the development of science, the progress of the society, the use of pesticides is becoming more and more extensive, and play an irreplaceable important role. In the same time, it also gives the quality and safety of agricultural products and the problems that cannot be ignored [1]. Pesticide residues have been widely concerned in the world, but also have a more stringent requirement on the residue limits, while the requirements for the detection technology is also growing [2].

Organic phosphorus and amino acid esters are the two major categories of pesticides in China [3]. Organic phosphorus pesticides used for the prevention and control of plant diseases, insects, and harm, this kind of pesticide varieties, high efficacy, wide use, easy decomposition, In person, the body does not accumulate, is a very important class of compounds in pesticides [4]. But there are many varieties of human, animal acute toxicity is very strong, such as: Ethoprophos, Sulfotep, Chlorpyrifos, Fenthion[5]. Amino acid esters, such as, Pirimicarb, Propoxur, Carbosulfan, Fenobucarb, is a novel broad-spectrum insecticidal, kill mites, herbicides. With the advantages of high efficiency and short duration, it has been widely used in agriculture, forestry and animal husbandry [6].
Therefore, it is important to establish the multi residue detection and analysis of organic phosphorus and amino acid esters in vegetables [7]. Refer to GB 2763-2014 Food safety national standards Maximum residue limits for pesticides in food [8], and these eight kinds of pesticides in consulting a large number of relevant documents and materials, the final choice of Ethoprophos, Sulfotep, Chlorpyrifos, Fenthion, Pirimicarb, Propoxur, Carbosulfan, Fenobucarb do as the object of study [9]. The Ethoprophos and Sulfotep are banned National pesticide, but GB 2763-2014 can still find residues on Sulfotep limits for $0.01 \mathrm{mg} / \mathrm{kg}$, which indicates that although the country banned the use of pesticides. But actual operation still has people in the production and use of these pesticides [10], so it has certain practical significance.

\section{Materials AND Methods}

\section{A. Materials}

Pesticide standard: 4 kinds of organic phosphorus pesticides (Ethoprophos, Sulfotep, Chlorpyrifos, Fenthion), 4 kinds of amino acid esters (Pirimicarb, Propoxur, Carbosulfan, Fenobucarb) Standard product: $100 \mu \mathrm{g} / \mathrm{mL}$. (The Ministry of Agriculture Research Institute of environmental protection supervision)

\section{B. Research Methods}

\section{1) GC / MS analysis}

GC: Chromatographic column:TG-5Ms Capillary column chromatography $(30 \mathrm{~m} \times 0.25 \mathrm{~mm} \times 0.25 \mu \mathrm{m})$; Carrier gas: High purity helium(Purity 99.9999\%); Current speed: $1.0 \mathrm{~mL} / \mathrm{min}$ (Constant linear velocity model); Column temperature: Starting temperature $50^{\circ} \mathrm{C}$, keep 1 minutes, temperature rise to 180 at $30 / \mathrm{min}$, keep 1 minutes, temperature rise to 280 at $15 / \mathrm{min}$, keep 10 minutes; Inlet temperature: $290^{\circ} \mathrm{C}$; Into the way: not to flow into the sample; Sample size: $1 \mu \mathrm{L}$.

MS: Ionization mode: electron bombardment ionization source(EI); Ionization energy:70ev; Ion source temperature: $230^{\circ} \mathrm{C}$; Interface temperature: $280^{\circ} \mathrm{C}$; Solvent cutting time: 5min; Tuning method: automatic tuning. Each pesticide choice: 1Quantitative ions, 2 qualitative ion monitoring (Table I). 
TABLE I. The Retention Time, Quantification Ions, CONFIRMATION IONS OF the 8 Pesticides

\begin{tabular}{|l|c|c|c|}
\hline \multirow{2}{*}{$\begin{array}{c}\text { Sample } \\
\text { Name }\end{array}$} & \multicolumn{3}{|c|}{ Retention Time and Characteristic Fragment Ion } \\
\cline { 2 - 4 } & Retention time (min) & $\begin{array}{c}\text { Quantitative } \\
\text { ion }\end{array}$ & $\begin{array}{c}\text { Qualitative } \\
\text { ion }\end{array}$ \\
\hline Ethoprophos & 8.26 & 158 & 200,242 \\
\hline Sulfotep & 8.59 & 322 & 202,238 \\
\hline Fenthion & 10.76 & 278 & 125,169 \\
\hline Chlorpyrifos & 10.78 & 314 & 258,311 \\
\hline Fenobucarb & 8.06 & 121 & 122,150 \\
\hline Propoxur & 8.09 & 110 & 152,111 \\
\hline Pirimicarb & 9.80 & 166 & 72,122 \\
\hline Carbosulfan & 13.64 & 160 & 118,135 \\
\hline
\end{tabular}

\section{2) Production of standard curve}

4 kinds of organic phosphorus pesticides and 4 kinds of amino acid esters: Accurate amount of pesticide standard, dissolution of ethyl acetate and constant volume to $1 \mathrm{~mL}$, standard reserve liquid, placed in the refrigerator for $4^{\circ} \mathrm{C}$. The mixed standard reserve liquid were diluted into standard series $(0.20 、 0.50 、 1.00 、 1.50 、 2.00 \mu \mathrm{g} / \mathrm{mL})$. Standard working solution for each concentration $1.0 \mu \mathrm{L}, \mathrm{GC} / \mathrm{Ms}$ determination and analysis, finally get standard curve of 8 pesticides.

\section{3) Sample pretreatment}

The Chinese cabbage, leek, tomato, radish (A special vegetable garden in Changping, each $1 \mathrm{Kg}$ ) added to the high-speed tissue grinder, each sample is accurately weighted $20 \mathrm{~g}$, Placed in a conical flask $(250 \mathrm{~mL})$, mixed $50 \mathrm{~mL}$ acetonitrile. Vortex oscillation $1 \mathrm{~min}$, ultrasonic shock $30 \mathrm{~min}$. Filtration residue removal, the resulting solution is poured into a graduate with a plug $(100 \mathrm{~mL})$ with $7 \mathrm{~g}$ Sodium chloride, Static stratification, Pass the night. Upper organic phase $15 \mathrm{~mL}$, placed in the $50 \mathrm{~mL}$ centrifuge tube, added $5 \mathrm{~g}$ anhydrous sodium sulfate, $8000 \mathrm{r} / \mathrm{min}$ Centrifugal $5 \mathrm{~min}$, take the supernatant $10 \mathrm{~mL}$ into the round bottom flask, rotary evaporation to $1 \sim 2 \mathrm{~mL}$, spare.

4) Purification of sample

$10 \mathrm{~mL}$ acetone activated amino solid phase extraction column, added to the purification solution, $10 \mathrm{~mL}$ hexane/acetone (V: V=50:50) eluting extraction column. Collecting and washing liquid, Rotary evaporation to dry, ethyl acetate content to $1.0 \mathrm{~mL}$, Over $0.22 \mu \mathrm{m}$ of the filter membrane, GC/MS detection.

\section{Results AND ANALysis}

\section{A. Selection of Extractive Solvent}

Acetonitrile, hexane, acetone and ethyl acetate are the commonly used solvents, the extraction effects of different solvents were tested respectively [11]. The results show, the average recovery rate of acetonitrile, hexane, acetone and ethyl acetate were $90.8 \%, 85.1 \%, 87.3 \%$ and $72.3 \%$ respectively; the extraction effect of acetonitrile is better than the other three kinds of extracting solvent (Figure 1).

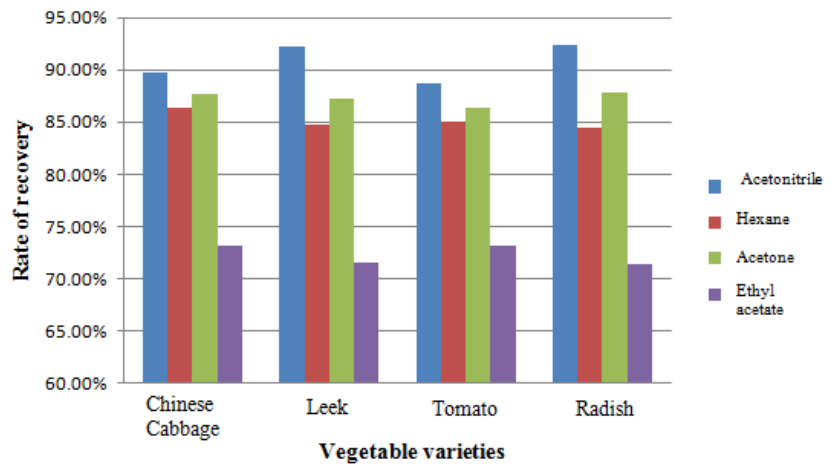

Figure 1. Comparison of four kinds of extracting solvent extraction

\section{B. Optimization of extraction method}

More commonly used extraction method: Centrifugal extraction of high-speed centrifuge, ultrasonic vibration extraction and vortex vibration extraction [12]. The three extraction methods were compared, the effect of vortex oscillation or ultrasonic extraction is poor, the recovery rate of pesticides was between $50 \% \sim 60 \%$, experiments show that the combination of these three methods, the recovery rate of pesticides is greatly improved, can reach more than $80 \%$. Therefore, this experiment chose three kinds of extraction methods [13].

\section{Optimization of volume of elution agent}

Due to the different types of pesticides to be measured, a mixed solvent method is usually used to carry out the elution. Test results: Hexane/acetone (V: $\mathrm{V}=50: 50)$ elution effect is good. In order to further study the effect of the amount of the solvent on the recovery rate, In this experiment we selected $5 \mathrm{~mL}, 10 \mathrm{~mL}, 15 \mathrm{~mL}$ of eluent on solid-phase extraction column leaching [13]. Result display, when the volume of the elution agent increases, the recovery rate of the pesticide will be improved, but the increase in the number of impurities. When the volume of the elution agent is $10 \mathrm{~mL}$, the recovery rate of most pesticides can reach more than $85 \%$. Therefore, this experiment chooses the $10 \mathrm{~mL}$ of the elution agent.

\section{Linear relationship and detection limit of the method}

Take 5 different concentrations of pesticide mixture standard working solution, in the best chromatographic conditions for its analysis, the concentration of pesticides as the horizontal coordinates, the peak area of pesticide is used as the vertical coordinate, linear regression analysis, the detection limit of the method is based on the sample adding level for low concentration, to three times the signal to noise ratio calculated. 


\section{E. Regression rate and precision of the method}

Take the vegetable sample and add the recovery test according to the above-mentioned method. Low, middle and high concentrations were tested, each concentration is set at
5 parallel, the average recovery was between $74.7 \sim 93.2 \%$, relative standard deviation in $8.08 \sim 9.17 \%$ which is adaptable to the pesticide residues analysis. ( Table II)

Table II. The Liner Range, Correlation Coefficient, Average Recovery Rate, RSD and Method Detection Limits of the 8 Pesticides

\begin{tabular}{|c|c|c|c|c|c|c|}
\hline Sample Name & $\begin{array}{c}\text { Linear range } \\
\boldsymbol{\mu g} / \mathbf{m L}\end{array}$ & Linear equation & $\begin{array}{c}\text { Correlation } \\
\text { coefficient }\end{array}$ & $\begin{array}{c}\text { Average } \\
\text { recovery rate } \\
\%\end{array}$ & $\begin{array}{c}\text { RSD\% } \\
\text { Method } \\
\text { detection limit } \\
\mathbf{m g} / \mathbf{k g}\end{array}$ \\
\hline Ethoprophos & $0.1 \sim 10$ & $\mathrm{y}=106931 \mathrm{x}+25267$ & 0.9987 & 85.7 & 9.17 & 0.0032 \\
\hline Sulfotep & $0.1 \sim 10$ & $\mathrm{y}=169063 \mathrm{x}+1903$ & 0.9995 & 87.1 & 9.03 & 0.0025 \\
\hline Fenthion & $0.1 \sim 10$ & $\mathrm{y}=391999 \mathrm{x}+11911$ & 0.9971 & 89.3 & 8.53 & 0.0042 \\
\hline Chlorpyrifos & $0.1 \sim 10$ & $\mathrm{y}=131974 \mathrm{x}+15111$ & 0.9974 & 93.2 & 8.08 & 0.0032 \\
\hline Fenobucarb & $0.1 \sim 10$ & $\mathrm{y}=119045 \mathrm{x}+23625$ & 0.9986 & 81.5 & 8.62 & 0.0032 \\
\hline Propoxur & $0.1 \sim 10$ & $\mathrm{y}=605238 \mathrm{x}+14519$ & 0.9965 & 84.3 & 8.55 & 0.0025 \\
\hline Pirimicarb & $0.1 \sim 10$ & $\mathrm{y}=719275 \mathrm{x}+29124$ & 0.9989 & 89.3 & 8.96 & 0.0080 \\
\hline Carbosulfan & $0.1 \sim 10$ & $\mathrm{y}=93268 \mathrm{x}+11554$ & 0.9972 & 74.7 & 8.56 & 0.0080 \\
\hline
\end{tabular}

\section{F. Sample determination}

This test method was used to detect the organic vegetables (Chinese cabbage, radish, cabbage and tomato) in the vegetable garden of Changping District. Test results show: The pesticide residues were not detected in the samples of organic vegetables from Changping special garden.

\section{DISCUSSION}

This research mainly aimed at four kinds of common organic vegetables, It is found that the detection of pesticide residues in organic vegetables is not much, but it doesn't mean that organic vegetables are absolutely safe. 8 kinds of organic phosphorus and amino acid esters were tested in the experiment, including Ethoprophos, Sulfotep, Chlorpyrifos, Fenthion, Pirimicarb, Propoxur, Carbosulfan, Fenobucarb. The Ethoprophos and Sulfotep are banned National pesticide, but GB 2763-2014 can still find residues on Sulfotep limits for $0.01 \mathrm{mg} / \mathrm{kg}$, which indicates that although the country banned the use of pesticides, but actual operation still has people in the production and use of these pesticides, there is a huge food safety hazard. In this study, a combination of solid phase extraction and gas chromatography mass spectrometry for simultaneous detection of multiple pesticide residues, test results show: The pesticide residues were not detected in the samples of organic vegetables from Changping special garden.

In this experiment, a solid phase extraction gas chromatography mass spectrometry method was developed for the simultaneous determination of 8 kinds of organic phosphorus and amino acid esters. The method has the advantages of simple treatment, good purification effect, easy operation and popularization. The average recovery was between 74.7 93.2\%, relative standard deviation in
8.08 9.17\%, the lowest detection limit of the method was between $0.0025 \sim 0.008 \mathrm{mg} / \mathrm{kg}$, all the indicators are in line

with the relevant requirements of pesticide residues in vegetables, and can provide a method for the detection of organic phosphorus and the residues of pesticides in vegetables.

\section{ACKNOWLEDGMENT}

Appreciate Beijing University of Agriculture provide the support and facilities on this research. At the same time, I also want to thank the teachers and the students who have given me help in the process of testing.

\section{REFERENCES}

[1] W.L. Zhao, "Weifang agricultural product quality safety regulatory problems and countermeasures research," Shandong University, 2014.

[2] Y. Ye, "Rapid detection of pesticide residues in food," Chinese food, vol. 16, pp. 38-39, 2014.

[3] Z.B. Chen, L.H. Liu, and Q. Ye, "Determination of Organophosphorus and Carbamate Pesticide Residues in Water by Gas Chromatography-Mass Spectrometry," Environ Health February, vol. 26(2), pp. 156-158, 2009.

[4] X.J. Xu, "Determination of 6 kinds of organic phosphorus pesticide residues in vegetables by gas chromatography," Qinghai agricultural extension, vol. 1, pp. 33-39, 2014.

[5] Z.X. Deng, "Retrospective analysis of organophosphorus pesticide poisoning patients with gastric lavage and catharsis process," China Foreign Medical Treatment, vol. 3, pp. 42-43, 2013.

[6] X. Liu, "Determination of Residues of Carbamate Pesticides on Ginkgo Biloba by Ultra Performance Liquid Chromatography/Mass Spectrometry," Shandong Forestry University, 2012.

[7] Q.Q. Hu, "Research of rapid Identification Technology of carbamate pesticide residues in Vegetables," Huazhong Normal University, 2009. 
[8] GB 2763-2014 Food safety national standards Maximum residue limits for pesticides in food.

[9] X.H. Gao, et al. Rapid detection of pesticide residue RP-410, China Geological Society, 2002.

[10] R. Wu, et al. "Study of agricultural products pesticide residue status and control measure in Shanxi," Chinese Journal of Health, vol. 11, pp. 2069-2071, 2007.
[11] J.H. Liu, et al. "Determination of Pesticides in Water by Solid-phase Extraction and in Sediment by Assisted Solvent Extraction with Gas Chromatography," Agrochemicals, vol. 1, pp. 44-46, 2010.

[12] Z.C. Fan, et al. "Multiresidue determination of 6 pyrethroid pesticides in flammulina velutipes," Food Sci, vol. 33(6), pp. 199-202, 2012.

[13] S. Yuan, et al. "Simultaneous determination of residues of 8 pyrethroid pesticides in vegetables with solid phase extraction-gas chromatography," Journal of Food Safety and Quality, vol. 6(5), pp. 1719-1725, 2015. 